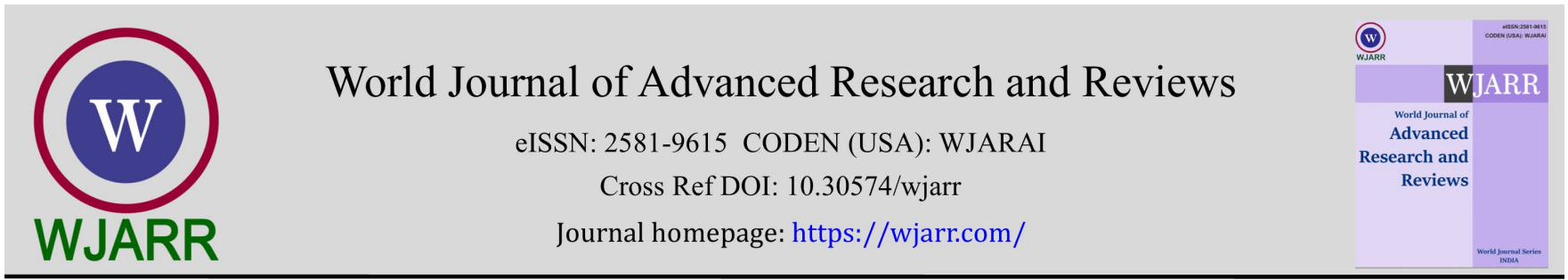

(RESEARCH ARTICLE)

\title{
Environmental, economic and energetic benefits from implantation of several modes of solar collector movements
}

\author{
Mustafa Hamad and Mhanna Obaid * \\ Palestine Technical University-Kadoorie, Tulkarm-Palestine.
}

World Journal of Advanced Research and Reviews, 2021, 12(03), 313-321

Publication history: Received on 16 October 2021; revised on 01 December 2021; accepted on 03 December 2021

Article DOI: https://doi.org/10.30574/wjarr.2021.12.3.0622

\begin{abstract}
In this research, the performance of a moving solar system on two axes was studied, the east-west axis, this axis represents the tilt angle of the solar collector. The other movement is the surface's rotation around the perpendicular axis on the surface in the east and west directions, which in turn represents the azimuth angle of the solar collector. All possibilities for these movements were also studied, in order to reach the optimal option, which in turn depends on the importance of alication and the available space on the one hand, and the economic conditions on the other hand. The maximum value of solar radiation intensity was adopted as a guide to compare the performance of six options for tracking systems. Despite the high costs of tracking systems, they often have a positive economic return, as these systems increase the efficiency of the solar system, whether it is electric or thermal twice, the first one by increasing the intensity of the solar radiation incident on the solar collector, and the second one by increasing the optical efficiency of the solar collectors and thus increasing the overall efficiency of the device. The percentage of increase in the sixth type of solar energy is about 38\% compared to the fixed mode. The minimum optical efficiency of the dual tracking mode has been found as $84 \%$, while for fixed mode is about $48 \%$.
\end{abstract}

Keywords: Solar tracking system; Fixed mode; One axis tracking mode; Dual axis tracking mode; Energetic benefit; Environmental impact

\section{Introduction}

The amount of solar radiation reaches on the exterior surface of the earth is a constant, but due to the difference in the tilt angle of the earth's axis leads to reduction on the solar radiation incident on the horizontal surfaces. For this reason, it is recommended to tilt surfaces to a certain tilt angle instead of horizontal surface. In an advanced stage, solar tracking systems had been adopted [1-3]. Solar energy is used in many engineering alications such as water desalination [4], heating and cooling homes and water [5-13], electricity generation [14-20], all of which use solar collectors.

Mechanisms that tracking the sun are the options to increase the intensity of the solar radiation falling on the solar conversion devices, whether thermal or electrical, in addition to the inverters. Despite its relatively high cost, the increase in the amount of energy covers these costs, in addition to being the only option in the event of limited space available to establish the station.

Three tracking systems are available and they are shown in Fig. 1. The system (1-A) presents the fixed mode, the system (1-B) rotates around the east-west axis, and it represents the tilt angle of the solar collector. While, the system (1-C) rotates around the perpendicular axis on the horizontal plane of the Earth, and it, in turn, represents the azimuth angle of the solar collector. These systems can work alone, but to obtain the highest value of solar radiation, a combination of systems (1-B) with (1-C) becomes necessary. The result will be a dual tracking system as shown it illustrates in Fig. (1-

\footnotetext{
${ }^{*}$ Corresponding author: Mhanna Obaid

Palestine Technical University-Kadoorie, Tulkarm-Palestine.

Copyright (C) 2021 Author(s) retain the copyright of this article. This article is published under the terms of the Creative Commons Attribution Liscense 4.0.
} 
D). The purpose of this research is to address all options for tracking the sun, and to obtain the values of the moving angles for each day and hour, as well as the corresponding value of the solar radiation incident on the solar collector.

To achieve this aim, a program was created in the FORTRAN language to simulate the proposed six options for tracking systems, which were as follows:

- The first option: The tilt angle $(\beta)$ is fixed and the azimuth angle $(\gamma)$ is fixed toward the south.

- The second option: The tilt angle is fixed and the azimuth angle is hourly moving.

- The third option: Daily moving of the tilt angle and the azimuth angle is fixed toward the south.

- The fourth option: Hourly moving of the tilt angle and the azimuth angle is fixed toward the south.

- The fifth option: Daily moving of the tilt angle and the azimuth angle is moving every hour.

- The sixth option: Hourly moving of both the tilt angle and the azimuth angle

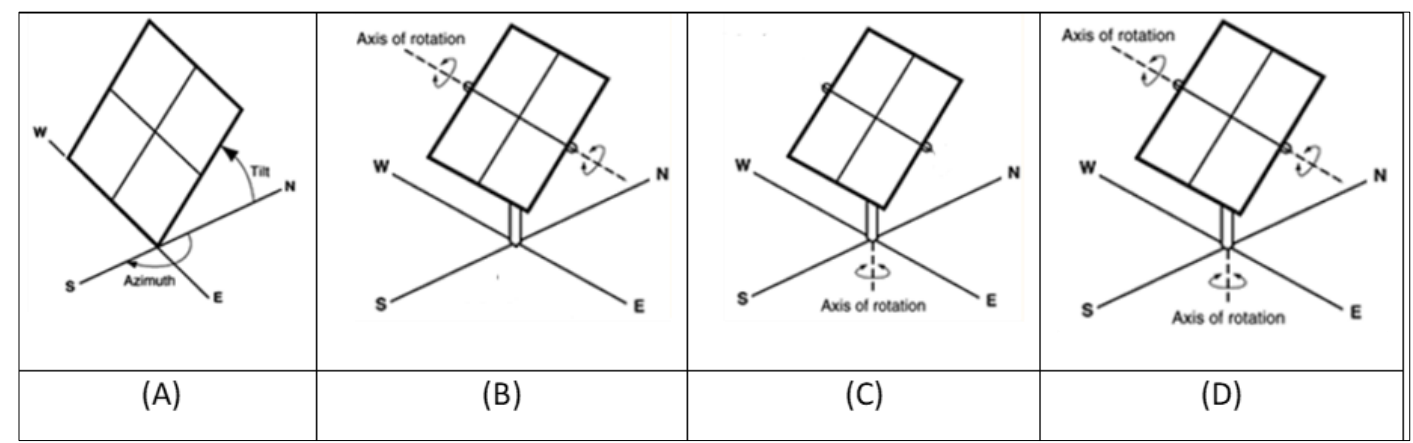

Figure 1 state of the problem

\section{Methodology}

Practically, it is difficult to find a mathematical model to represent the movement of tracking systems, due to its great dependence on the sky condition $[21,22]$. In cloudy times, it is necessary that the angle of inclination of the solar collector be horizontal to increase the amount of the sky-diffuse irradiation component than the rest of the components, and of course these times cannot be expected. But if the sky is clear, the tilt and azimuth angles of the surface change with time according to the position of the sun in the sky. For this reason, the clear sky model was adopted to calculate the intensity of solar radiation in this study [23].

Table 1 The emission factor for Natural Gas for electric utility

\begin{tabular}{|c|c|c|}
\hline No & Air emission & Emission Factor $\mathbf{( g / \mathbf { m } ^ { 3 } )}$ \\
\hline 1 & $\mathrm{CO}_{2}$ & 1.009 \\
\hline 2 & $\mathrm{CH}_{4}$ & 0.49 \\
\hline 3 & $\mathrm{~N}_{2} \mathrm{O}$ & 0.049 \\
\hline 4 & $\mathrm{PM}$ & 0.04 \\
\hline 5 & $\mathrm{SO}_{2}$ & 0.0096 \\
\hline 6 & $\mathrm{NO}_{2}$ & 2.24 \\
\hline 7 & $\mathrm{VOC}$ & 0.044 \\
\hline 8 & $\mathrm{CO}$ & 0.56 \\
\hline \multicolumn{2}{|c|}{$\mathrm{CO}_{2} \mathrm{e}$} & 1,930 \\
\hline
\end{tabular}


The methodology for estimating the solar irradiation incident on a tilted surface and facing to a certain azimuth angle is well documented in all text books of solar energy engineering [1] and reported in many research papers [24-29].

The environment analysis has been carried according to [30-36]. Table 1 tabulates the emission factors of several air emissions [30]

\section{Results and discussion}

\subsection{Optimum tilt and azimuth angles}

Fig. 2 represents the relationship between the optimum tilt angles of a solar collector $\left(\beta_{\text {opt }}\right)$ for the fixed mode (The first option) in terms of the latitude angle $(\lambda)$ for the northern hemisphere. The curve in Fig. 2 can be represented by the following relationship:

$$
\begin{gathered}
\beta_{\text {opt }}=-2 \times 10^{-9} \lambda^{6}+6 \times 10^{-7} \lambda^{5}-7 \times 10^{-5} \lambda^{4}+0.0033 \lambda^{3}-0.0759 \lambda^{2}+1.5755 \lambda+1.9351, \\
R^{2}=0.9992
\end{gathered}
$$

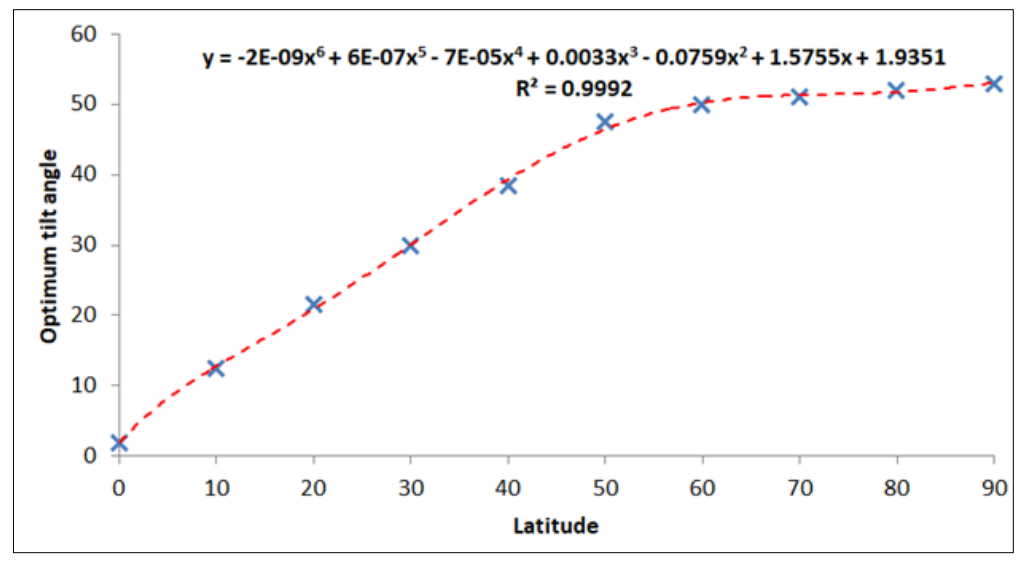

Figure 2 The relationship between the tilt angle of solar collector and the site's latitude (The first option)

While Fig. 3 demonstrates the relationship between the optimum tilt angles of a solar collector ( $\left.\beta_{\text {opt }}\right)$ for fixed tilt angle and hourly moving of the azimuth angle (The second option) in terms of the latitude angle ( $\lambda$ ) for the northern hemisphere. The curve in Fig. 3 can be represented by the following relationship:

$$
\begin{gathered}
\beta_{\text {opt }}=-3 \times 10^{-9} \lambda^{6}+7 \times 10^{-7} \lambda^{5}-7 \times 10^{-5} \lambda^{4}+0.0028 \lambda^{3}-0.0438 \lambda^{2}+0.3059 \lambda+45.014, \\
R^{2}=0.9987
\end{gathered}
$$

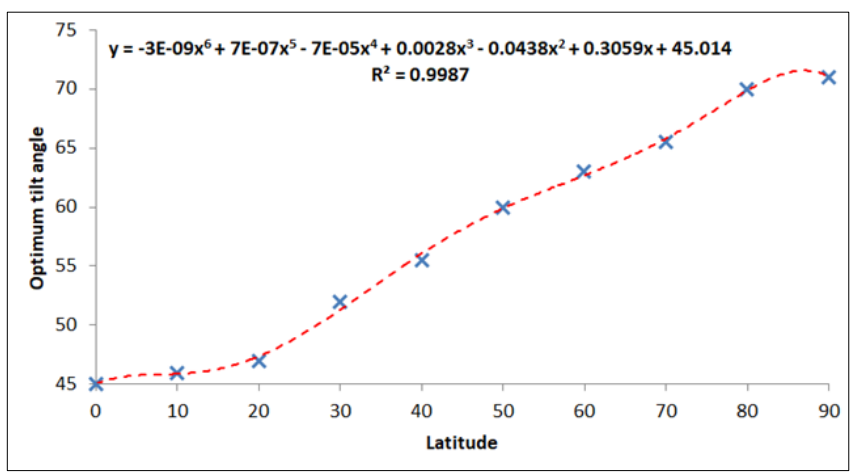

Figure 3 The relationship between the tilt angle of solar collector and the site's latitude (The second option) 
Fig. 4 represents the relationship between the tilt angles which is moving one movement every day, with the latitude for the $21^{\text {st }}$ of every month, for the third option when the angle of the surface direction towards the south is fixed. The negative sign for the months of March to September indicates that the sun at noon times is behind the surface, and therefore the surface must tilt in the oosite direction that in the north direction.

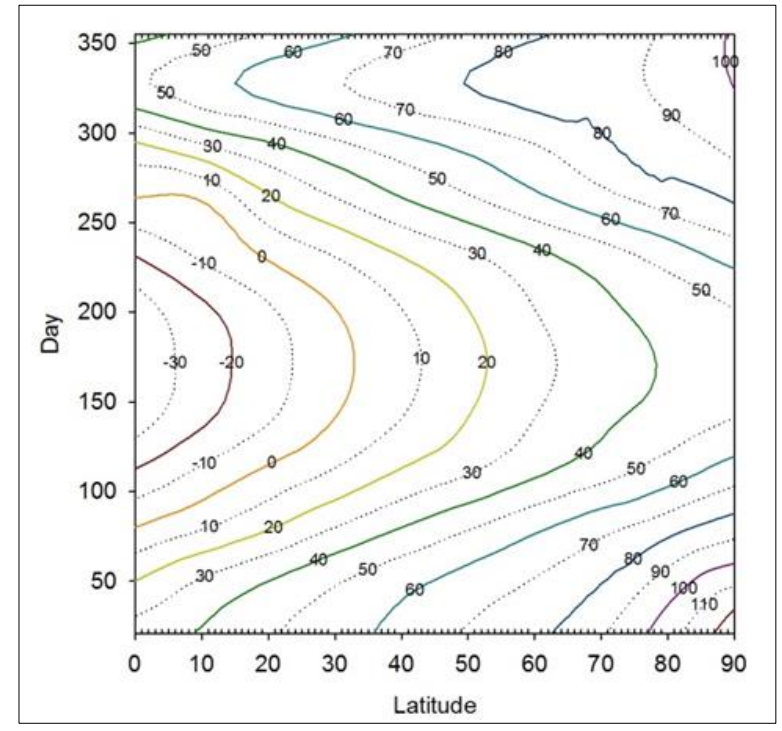

Figure 4 The optimum tilt angle of solar collector according to the site's latitude for the day $21^{\text {st }}$ every month (The third option)

While, Fig. 5 represents the relationship between the tilt angle which is moving one movement every hour, with the latitude for the $21^{\text {st }}$ of every month and at exactly 11:00, and when the angle of the surface towards the south is fixed for the fourth option.

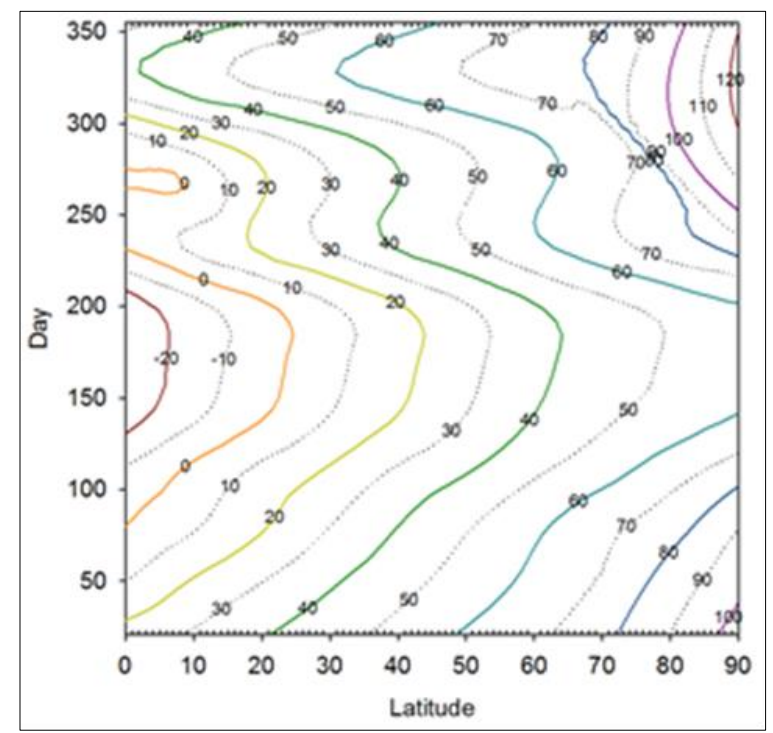

Figure 5 The optimum tilt angle of solar collector according to the site's latitude at 11:00 for the day $21^{\text {st }}$ every month (The fourth option)

\subsection{Energetic evaluation}

The total daily solar radiation incident on a solar collector of optimum tilt angle and optimum azimuth angle were also calculated for the day of $21^{\text {st }}$ of every month, and the results were graphically represented as a bubble with 3-D effect chart (Fig.6), and the annual solar radiation shown in Table.2. 


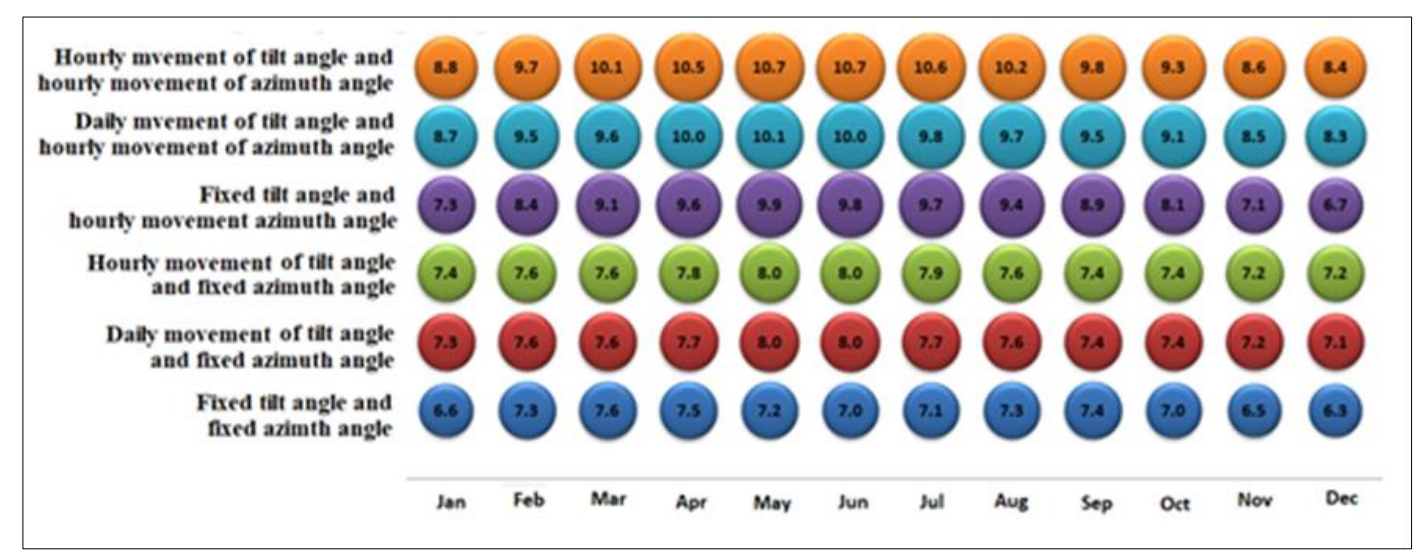

Figure 6 A comparison of total daily solar radiation incident $\left[\mathrm{kW} / \mathrm{m}^{2}\right]$ on a solar collector for all options at the day of $21^{\text {st }}$ of every month

Table 2 Total solar radiation incident on a $1 \mathrm{~m}^{2}$ area of a flat solar collector $\left[\mathrm{kW} / \mathrm{m}^{2}\right]$

\begin{tabular}{|l|l|c|}
\hline Options & System & Annual solar radiation, $\mathbf{k W} / \mathbf{m}^{\mathbf{2}}$ \\
\hline One & Fixed $\beta$ and fixed $\gamma$ & 2577.72 \\
\hline Two & Daily movement $\beta$ and fixed $\gamma$ & 2753.637 \\
\hline Three & Hourly movement $\beta$ and fixed $\gamma$ & 2768.803 \\
\hline Four & Fixed $\beta$ and hourly movement $\gamma$ & 3164.518 \\
\hline Five & Daily movement $\beta$ and hourly movement $\gamma$ & 3432.087 \\
\hline Six & Hourly movement $\beta$ and hourly movement $\gamma$ & 3565.995 \\
\hline
\end{tabular}

\subsection{Optical efficiency}

Solar thermal and electrical conversion systems often use transparent covers on the user surface of the system to protect it from weather erosion factors, and although these covers reduce the overall efficiency of the device due to their optical efficiency, their use is necessary either to reduce heat losses in the case of thermal systems or to protect the solar cells from environmental factors. Optical efficiency ( $\left.\eta_{\text {opt }}\right)$ is the product of two optical properties of the system ( $\left.\tau \alpha\right)$. The first property represents the transmittance $(\tau)$, which is an optical property of the transparent cover (glass or plastic), and it is a function of the solar incident angle, while the second property is the absorbance of the absorbent plate $(\alpha)$.

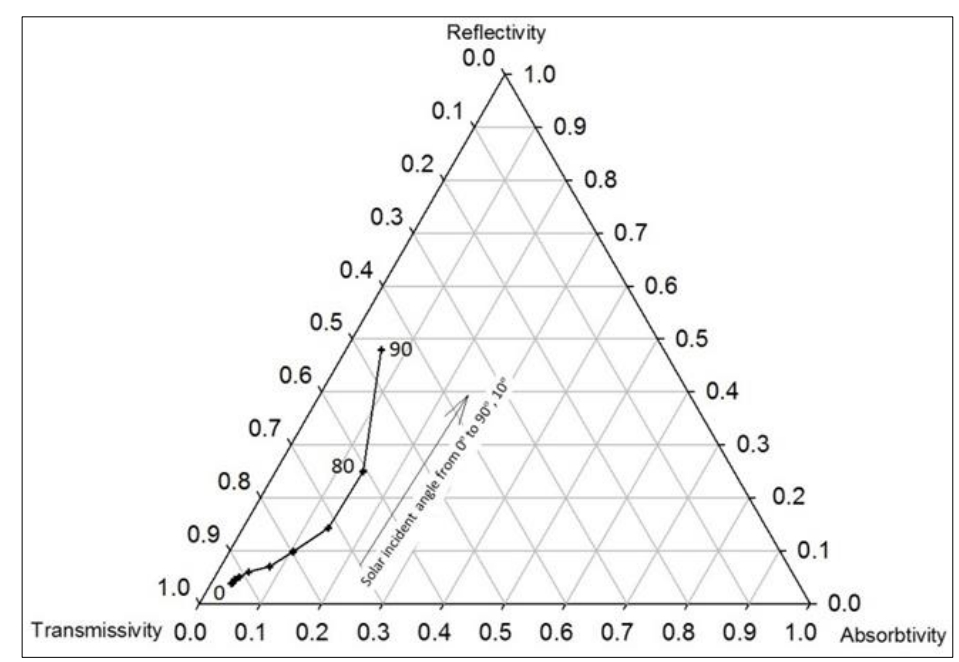

Figure 7 Ternary plot for optical properties of a glass cover of a solar collector as a function in solar incident angle 
The transmittance property of transparent fabrics is highly dependent on the angle of incidence of the solar ray, the lower this angle, the higher the value of the transmittance, and by increasing it, the optical efficiency increases, and this in turn leads to an overall rise in the performance of the system as a whole.

Fig. 7 shows the relationship of the optical properties of the glass with the angle of incidence. Table 3 shows the largest and smallest range of optical efficiency of a flat solar collector for a number of options of systems tracking the aarent movement of the sun. As is clear from Table 3, the sixth system has almost constant optical efficiency, and this indicates the success of the tracking systems in making the angle of incidence almost perpendicular to the surface of the solar conversion system (as is clear in Fig. 7). As for the rest of the systems, the deviation from the average is large, and this In turn, it indicates the failure of these options to reduce the value of the angle of incidence.

Table 3 Maximum and minimum values of the optical efficiency

\begin{tabular}{|l|l|c|c|}
\hline Options & System & $\mathbf{M a x}^{\mathbf{m}} \boldsymbol{\eta}_{\text {opt }}$ & $\mathbf{M i n}^{\mathbf{m}} \boldsymbol{\eta}_{\text {opt }}$ \\
\hline One & Fixed $\beta$ and fixed $\gamma$ & 84.29 & 48.41 \\
\hline Two & Daily movement $\beta$ and fixed $\gamma$ & 84.29 & 48.41 \\
\hline Three & Hourly movement $\beta$ and fixed $\gamma$ & 84.29 & 58.02 \\
\hline Four & Fixed $\beta$ and hourly movement $\gamma$ & 84.29 & 48.41 \\
\hline Five & Daily movement $\beta$ and hourly movement $\gamma$ & 84.29 & 48.41 \\
\hline Six & Hourly movement $\beta$ and hourly movement $\gamma$ & 84.29 & 84.29 \\
\hline
\end{tabular}

Accordingly, Fig. 8 represents the average values of the hourly solar incident angles and the maximum and minimum deviations throughout the year for the sixth option mode for the city of Hebron

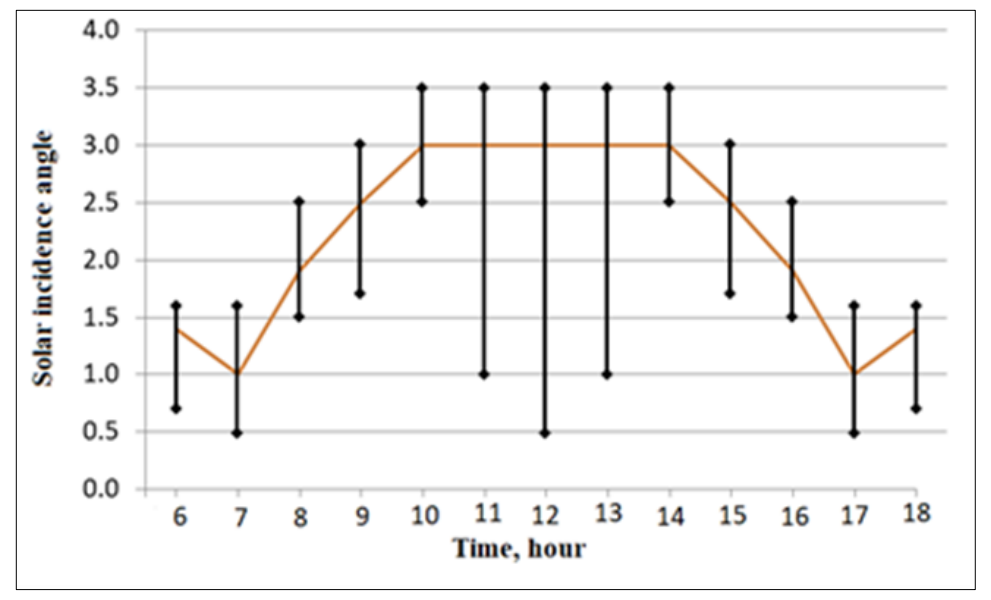

Figure 8 The hourly average values of the solar incidence angle and the maximum and minimum deviation

\subsection{Economic evaluation}

Despite the high costs of tracking systems (about $\$ 120$ per mobile model), they often have a positive economic return, as these systems work (in the case of flat roofs) to increase the efficiency of the solar system, thermal (planar solar collectors) or electrical (solar panels). ). Table 4 shows the amount of fuel that was saved due to the use of solar tracking systems for every 100 square meters of solar conversion systems. 
Table 4 The amount of fuel saved from the six options for an area of $100 \mathrm{~m}^{2}$ of solar collectors

\begin{tabular}{|l|l|c|c|c|}
\hline Options & System & $\begin{array}{l}\text { Equivalent Oil } \\
(\mathbf{k g})\end{array}$ & $\begin{array}{l}\text { Crude Oil } \\
(\mathbf{b a r r e l )}\end{array}$ & $\begin{array}{l}\text { Natural Gas } \\
\left(\mathbf{m}^{\mathbf{3}} \mathbf{)}\right.\end{array}$ \\
\hline One & Fixed $\beta$ and fixed $\gamma$ & - & - & - \\
\hline Two & Daily movement $\beta$ and fixed $\gamma$ & 2,240 & 11.39 & 2,811 \\
\hline Three & Hourly movement $\beta$ and fixed $\gamma$ & 2,350 & 11.93 & 2,897 \\
\hline Four & Fixed $\beta$ and hourly movement $\gamma$ & 7,290 & 37.07 & 5,894 \\
\hline Five & Daily movement $\beta$ and hourly movement $\gamma$ & 10,640 & 54.11 & 8,603 \\
\hline Six & Hourly movement $\beta$ and hourly movement $\gamma$ & 12,170 & 61.93 & 9.847 \\
\hline
\end{tabular}

\subsection{Environmental evaluation}

Table 5 shows the annual total air emissions that saved due to adopting solar conversion systems for the six options, on the base of the air emissions factors that documented in [30-36]. The emission factor is taken as $840.8 \mathrm{~kg} / \mathrm{MWh}$ [30].

Table 5 The amount of air emissions saved from the six options for an area of $1 \mathrm{~m} 2$ of solar collectors

\begin{tabular}{|l|l|c|}
\hline Options & System & $\begin{array}{c}\text { Annual saving of } \mathbf{C O}_{2} \text { emission } \\
{\left[\mathbf{k g} / \mathbf{m}^{2} \text { solar collector }\right]}\end{array}$ \\
\hline One & Fixed $\beta$ and fixed $\gamma$ & 2167.347 \\
\hline Two & Daily movement $\beta$ and fixed $\gamma$ & 2315.258 \\
\hline Three & Hourly movement $\beta$ and fixed $\gamma$ & 2328.01 \\
\hline Four & Fixed $\beta$ and hourly movement $\gamma$ & 2660.727 \\
\hline Five & Daily movement $\beta$ and hourly movement $\gamma$ & 2885.699 \\
\hline Six & Hourly movement $\beta$ and hourly movement $\gamma$ & 2998.289 \\
\hline
\end{tabular}

\section{Conclusion}

In this research, the performance of a moving solar system on two axes was studied, the east-west axis, this axis represents the tilt angle of the solar collector. The other movement is the surface's rotation around the perpendicular axis on the surface in the east and west directions, which in turn represents the azimuth angle of the solar collector. All possibilities for these movements were also studied, in order to reach the optimal option, which in turn depends on the importance of alication and the available space on the one hand, and the economic conditions on the other hand. The maximum value of solar radiation intensity was adopted as a guide to compare the performance of six options for tracking systems. Despite the high costs of tracking systems, they often have a positive economic return, as these systems increase the efficiency of the solar system, whether it is electric or thermal twice, the first one by increasing the intensity of the solar radiation incident on the solar collector, and the second one by increasing the optical efficiency of the solar collectors and thus increasing the overall efficiency of the device. The percentage of increase in the sixth type of solar energy is about $38 \%$ compared to the fixed mode. The minimum optical efficiency of the dual tracking mode has been found as $84 \%$, while for fixed mode is about $48 \%$.

\section{Compliance with ethical standards}

\section{Acknowledgments}

The researchers would like to thank Palestine Technical University- Kadoorie (PTUK) for continuous support the applied research. 


\section{Disclosure of conflict of interest}

The authors hereby declare there is no conflict of interest.

\section{References}

[1] Nassar Y. Solar energy engineering active alications, Sabha University, Libya .2006.

[2] Nassar Y. Simulation of solar tracking systems, Energy \& Life Journal. 2005; 21: 81-90.

[3] Nassar Y, Hadi H, Salem A. Time Tracking of the Shadow in the Solar Fields, J. Sebha Univ. 2008; 7(2): 59-73.

[4] Nassar Y, Yousif S, Salem A. The second generation of solar desalination systems, Desalination. 2007; 209: 177181.

[5] Nassar YF, Sergievsky ED. Heat transfer in flat-plate solar air-heating collectors, Sixth international conference on advanced computational methods in heat transfer, Heat Transfer 2000, Madrid. June 2000; 575-584.

[6] Nassar Y, Salem A. The utilization concept of the thermal storage in solar heating systems, International forum on renewable energies -FIRE 2002, Tetuan, Morocco. 2002; 389-394.

[7] Nassar Y, Alsadi S, Amer K, Yousef A, Fakher M. Numerical Analysis and Optimization of Area Contribution of The PV Cells in the PV/T Flat-Plate Solar Air Heating Collector, Solar Energy Research. 2019.

[8] Nassar Y, ElNoaman A, Abutaima, A, Yousif S, Salem A. Evaluation of the underground soil thermal storage properties in Libya, Renewable energy. 2006; 31(5): 593-598.

[9] Nassar Y. Thermodynamics analysis and optimization procedure for domestic solar water heating system, AASCIT, American Journal of Energy and Power Engineering. 2015; 2(6): 92-99.

[10] Nassar Y, Salem A. Solar energy \& energy conservation in buildings, 1st International Congress of MechanicsConstantine Faculty of Engineering Department of Mechanical Engineering, University of Constantine, Algeria. December 2002; 14-16.

[11] Nassar YF. Development of solar heating systems, Ph.D. thesis, Moscow Power Engineering Institute (Technical University), Moscow. (In Russian language). 1999.

[12] Nassar Y, Salem A, Sergievsky E. A creation of mathematical model for photovoltaic/ thermal (PV/T) solar flatplate collector, International conference on renewable energy for regional development CIGA, Bogor - Indonesia. $2001 ; 28-31$.

[13] Nassar Y, Sharif M. Economic and Energetic analysis for optimizing the length of flat-plate solar air heating collectors, Alied Mechanics and Materials. 2014; 446: 810-816.

[14] Nassar Y, Salem A. The reliability of the photovoltaic utilization in southern cities of Libya, Desalination. 2007; 209: 86-90.

[15] Salem A, Nassar Y, Yousif S. The Choice of Solar Energy in the Field of Electrical Generation-Photovoltaic or Solar Thermal - For Arabic Region, World Renewable Energy Congress VIII (WREC 2004). b2004.

[16] Alsadi S, Nassar Y. A general expression for the shadow geometry for fixed mode horizontal, step-like structure and inclined solar fields, Solar Energy. 2019; 181: 53-69

[17] Awad H, Nassar Y, Hafez A, Sherbiny M, Ali A. Optimal design and economic feasibility of rooftop photovoltaic energy system for Assuit University, Egypt, Ain Shams Engineering Journal. 2021.

[18] Ali A, Karram E, Nassar Y, Hafez A. Reliable and economic isolated renewable hybrid power system with pumped hydropower storage, 22th international Middle East power systems conference (MEPCON 2021), Assiut University, Assiut-Egypt. 2021.

[19] Hafez A, Nassar Y, Hammdan M, Alsadi S. Technical and Economic Feasibility of Utility-Scale Solar Energy Conversion Systems in Saudi Arabia, Iranian Journal of Science and Technology, Transactions of Electrical Engineering, Transactions of Electrical Engineering. 2019.

[20] Alsadi S, Nassar N. General polynomial for optimizing the tilt angle of flat solar energy harvesters based on ASHRAE clear-sky model in mid and high latitudes, Energy and Power. 2016; 6(2).

[21] Alsadi S, Nassar Y. Energy demand based procedure for tilt angy, le optimization of solar collectors in developing countries, Journal of Fundamentals of Renewable Energy and Alications. 2017; 7: 225. 
[22] Alsadi SY, Nassar YF. Correction of the ASHRAE Clear-Sky Model Parameters Based on Solar Radiation Measurements in the Arabic Countries. International Journal of Renewable Energy Technology Research. 2016; 5: $1-16$

[23] Alsadi S, Nassar Y. Estimation of Solar Irradiance on Solar Fields: An Analytical Aroach and Experimental Results. IEEE Transactions on Sustainable Energy. 2017; 8(4): 1601-1608.

[24] Nassar Y, Hafez A, Alsadi S. Multi-Factorial Comparison for 24 Distinct Transposition models for Inclined Surface Solar Irradiance Computation in the State of Palestine: A Case Study. Front. Energy Res. 2020; 7: 163.

[25] Nassar Y. Analytical-numerical computation of view factor for several arrangements of two rectangular surfaces with non-common edge, International Journal of Heat and Mass Transfer. 2020; 159.

[26] Nassar Y, Alsadi S. View factors of flat solar collectors array in flat, inclined, and step-like solar fields. J. Solar Energy Eng. ASME Trans. 2016; 138: 1-8.

[27] Nassar Y, Alsadi S. Assessment of solar energy potential in Gaza Strip-Palestine ,Sustainable Energy Technologies and Assessments. 2019; 31: 318-328.

[28] Asadi Y, Nassar Y. A Numerical Simulation of a Stationary Solar Field Augmented by Plane Reflectors: Optimum Design Parameters, Smart Grid and Renewable Energy. 2017; 8(7): 221-239.

[29] Nassar Y, Aissa K, Alsadi S. Air Pollution Sources in Libya. Research \& Reviews: Journal of Ecology and Environmental Sciences. 2017; 5: 63-79.

[30] Nassar Y, Salem M, Iessa K, AlShareef I, Amer K, Fakher M. Estimation of CO2 emission factor for the energy industry sector in libya: a case study. Env. Dev. Sustain. 2021.

[31] Nassar Y, Aissa K, Alsadi S. Estimation of Environmental Damage Costs from CO2e Emissions in Libya and the Revenue from Carbon Tax Implementation. Low Carbon Economy. 2017; 8: 118-132.

[32] Yousif S, Salem A, Nassar Y, Bader I. Investigation of pollutants dispersion from power stations, international journal of energy research. 2006; 30(15): 1352-1362.

[33] Nassar Y, Alsadi S. Economic and environmental feasibility of the renewable energy as a sustainable solution for the electricity crisis in the Gaza Strip, International Journal of Engineering Research and Development. 2016; 12(3): 35-44.

[34] Nassar Y, Alsadi S. Wind energy potential in Gaza Strip-Palestine state, Solar Energy and Sustainable Development. 2018; 7(2): 41-57.

[35] Nassar Y, Amer K, Irhouma M, Ahmad S. Economic and environmental assessment of electrical generators: A case study of southern region of Libya, International Journal of Energy Policy and Management. 2015; 1(4): 64-71. 